\title{
Association analysis of cigarette smoking with onset of primary open-angle glaucoma and glaucoma-related biometric parameters
}

Degui Wang ${ }^{1}$, Yuqiang Huang ${ }^{1}$, Chukai Huang ${ }^{1}$, Pengfei Wu', Jianwei Lin'1, Yuqian Zheng ${ }^{1}$, Yi Peng ${ }^{2}$, Yuanbo Liang ${ }^{2}$, Jian-Huan Chen ${ }^{1,2^{*}}$ and Mingzhi Zhang ${ }^{1 *}$

\begin{abstract}
Background: To date, studies on the role played by cigarette smoking in primary open-angle glaucoma (POAG) remains controversial. The current study evaluated cigarette smoking as a risk factor of POAG and its relationships with vertical cup-to-disc ratio (VCDR), central corneal thickness (CCT) and intraocular pressure (IOP) in a Chinese cohort.

Methods: In a total of 248 unrelated individuals including 30 juvenile-onset POAG (JOAG), 92 adult-onset POAG $(\mathrm{AOAG})$ and 126 sex-matched senile cataract controls, underwent comprehensive ophthalmic examination. Their smoking was obtained and documented by questionnaire. Association of cigarette smoking with POAG was performed using logistic regression controlled for age and sex. Effects of cigarette smoking on VCDR, IOP and CCT were analyzed with multiple linear regression.

Results: In either JOAG or AOAG, no association of cigarette smoking was found with disease onset $(P=0.692$ and 0.925 respectively). In controls and JOAG, no significant effects of smoking were found on VCDR, IOP or CCT (all $P>$ 0.05). Smoking was found to be correlated with decreased CCT in AOAG and combined POAG (JOAG + AOAG) $(P=$ 0.009 and 0.003$)$, but no association with VCDR or IOP was observed $(P>0.05)$.

Conclusions: Although cigarette smoking was not found to be risk factor for onset of POAG, it was correlated with $C C T$ in $A O A G$, and thus might still play a role in the disease course, especially for AOAG.
\end{abstract}

Keywords: Primary open angle glaucoma, Cigarette smoking, Central corneal thickness, Vertical cup-to-disc ratio, Intraocular pressure

\section{Background}

Primary open-angle glaucoma (POAG) is a group of disorders characterized by loss of retinal ganglion cells associated with optic nerve degeneration and visual field loss. It's the second leading cause of visual loss and blindness worldwide, and affected 60 million people [1]. POAG is associated with many clinical features, including vertical cup-to-disc ratio (VCDR), central corneal thickness (CCT) and intraocular pressure (IOP). According to age of disease onset, there are two categories of

\footnotetext{
* Correspondence: cjh_bio@hotmail.com; zmz@jsiec.org

'Joint Shantou International Eye Center, Shantou University \& the Chinese University of Hong Kong, Shantou, China

${ }^{2}$ Department of Ophthalmology and Visual Sciences, The Chinese University of Hong Kong, Hong Kong, China
}

\section{Biomed Central}

(c) 2012 Wang et al.; licensee BioMed Central Ltd. This is an Open Access article distributed under the terms of the Creative Commons Attribution License (http://creativecommons.org/licenses/by/2.0), which permits unrestricted use, distribution, and reproduction in any medium, provided the original work is properly cited.
POAG: adult-onset POAG (AOAG, disease onset after 40 years) and juvenile-onset POAG (JOAG, disease onset between 3 and 40 years) [2]. Reported risk factors of POAG include cigarette smoking, hypertension, diabetes, and family history [3-5]. Although existing studies have reported the association between cigarette smoking and POAG [6,7], the role of cigarette smoking as a risk factor of POAG remains controversial [8,9]. And most of these studies focused on AOAG. Especially, there are limited data of these studies in the Chinese population. In this study we investigated the association of cigarette smoking with POAG, and its relationship with VCDR, CCT and IOP in a Southern Chinese cohort. 
Table 1 Demographic features of the study subjects

\begin{tabular}{|c|c|c|c|c|c|c|c|c|c|c|}
\hline \multirow{2}{*}{\multicolumn{2}{|c|}{$\mathrm{N}$}} & \multirow[t]{2}{*}{ Female } & \multicolumn{2}{|c|}{ Age (Year) } & \multicolumn{2}{|c|}{ VCDR } & \multicolumn{2}{|c|}{ IOP $(\mathrm{mmHg})$} & \multicolumn{2}{|c|}{$\mathrm{CCT}(\mu \mathrm{M})$} \\
\hline & & & Mean & SD & Mean & SD & Mean & SD & Mean & SD \\
\hline Control & 126 & 29 & 69.5 & 8.9 & 0.32 & 0.06 & 13.3 & 2.6 & 541.7 & 36.1 \\
\hline JOAG & 30 & 6 & 25 & 6 & 0.86 & 0.17 & 34.1 & 11.4 & 542.6 & 21.9 \\
\hline AOAG & 92 & 14 & 59.9 & 12.1 & 0.84 & 0.14 & 31.5 & 10.9 & 533.9 & 36.4 \\
\hline
\end{tabular}

\section{Methods}

\section{Patient recruitment and clinical information}

The study subjects were unrelated, and included 122 POAG patients and 126 controls recruited at the Joint Shantou International Eye Center in Shantou, China from March, 2008 to November, 2011 (Table 1). Both POAG patients and controls received comprehensive ophthalmic examination. Their highest IOP of both eyes before medication, maximum VCDR of both eyes, and mean CCT were documented when they were first presented to the clinic. The highest IOP was measured using Goldman Ocular tonometry. VCDR and CCT were measured using a standard protocol. Before measuring, a single drop of proparacaine 1\% (Alcaine, Alcon Laboratories, Ft. Worth TX) was placed in the eye. VCDR was measured by an experienced glaucoma specialist, and then confirmed by another experienced glaucoma specialist. IOP was measured by an experienced glaucoma specialist using Goldmann applanation tonometry, and recorded as the mean of three measurements. CCT was measured ultrasonically (IOPac $20 \mathrm{Mhz}$ Pachymeter, Heidelberg Engineering, Germany). A total of 10 measurements were made for each eye, with additional measurements obtained if the standard deviation exceeded 10 microns. Visual field function was assessed using the Glaucoma Hemifield test (Humphrey automated perimetry, Carl Zeiss Meditec, Inc., Germany). Cigarette smoking status was obtained by questionnaire (Additional file 1), and active smoking was defined as smoking at least 5 cigarettes per day for in the past one or more years [3].

The diagnosis of POAG was based on the following inclusion criteria: (1) gonioscopically open anterior chamber angle, Shaffer grade III or IV; (2) characteristic optic disc damage and/or typical visual field loss; (3) highest IOP > $21 \mathrm{mmHg}$; (4) exclusion of secondary causes, e.g., trauma, uveitis, steroid-induced or exfoliation glaucoma. Juvenile-onset POAG (JOAG) was recruited based on age of disease onset between 3 and 40 years, and adultonset POAG (AOAG) based on disease onset after 40 years. The control subjects were recruited from senile cataract surgical inpatients aged 50 and older without family history of glaucoma. All of the controls have IOP $<21 \mathrm{mmHg}, \mathrm{VCDR}<0.5$, and no sign of visual field loss. Eyes met the following criteria were excluded: any history or symptom of keratopathy, Marfan's syndrome, ocular trauma, ocular surgery in prior to the recruitment, macular epiretinal membrane, macular edema, macular hemorrhage, retinal detachment, or severe cataract affecting the results of examination.

This study was approved by the Ethics Committee of Joint Shantou International Eye Center and was conducted in accordance with the Declaration of Helsinki. Written consent was obtained from each participating subject after explanation of the nature of the study.

\section{Statistical analysis}

Association and interaction analysis was performed using multiple regression implemented by the $\mathrm{R}$ statistical Language version 2.15.0. Association between cigarette smoking and disease was assessed in both JOAG and AOAG by logistic regression controlled age and sex. Multiple linear regression was used to analyze effects of cigarette smoking on VCDR, IOP and CCT. Two-factor interaction between smoking and age/sex was evaluated in both logistic and linear regression.

\section{Results}

\section{Patients and clinical data}

Their clinical features were shown in Table 1. Among POAG patients, 30 were diagnosed as juvenile-onset POAG (JOAG), 92 as adult-onset POAG (AOAG). Ocular hypertension and signs of optic disc neuropathy were found in these POAG patients, but were absent in all 126 senile cataract controls.

Table 2 Association of cigarette smoking with JOAG and AOAG in the current cohort

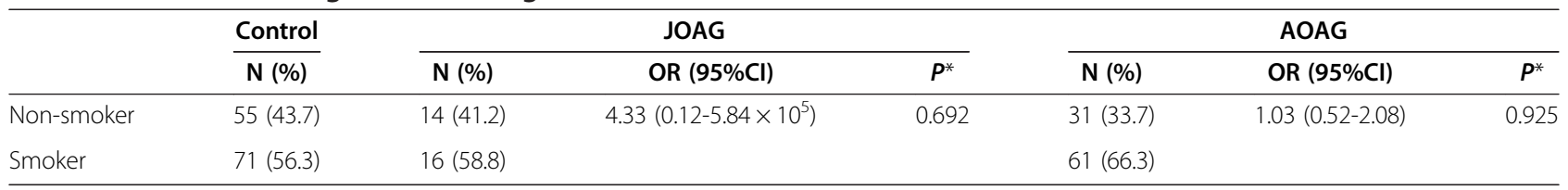

${ }^{*} P$-values are adjusted to age and sex. 
Table 3 Multiple linear regression analysis of effects of smoking, age and female sex on vertical cup-to-disc ratio

\begin{tabular}{|c|c|c|c|c|c|c|c|c|}
\hline & \multicolumn{2}{|c|}{ Controls } & \multicolumn{2}{|c|}{ JOAG } & \multicolumn{2}{|c|}{ AOAG } & \multicolumn{2}{|c|}{ JOAG + AOAG } \\
\hline & $\beta$ (SE) & $P$ & $\beta$ (SE) & $P$ & $\beta$ (SE) & $P$ & $\beta$ (SE) & $P$ \\
\hline Smoking (Yes) & $-0.003(0.016)$ & 0.867 & $-0.101(0.069)$ & 0.156 & $-0.019(0.035)$ & 0.590 & $-0.031(0.0290$ & 0.294 \\
\hline Age (Year) & $0.025(0.017)$ & 0.150 & $0.011(0.081)$ & 0.893 & $-0.053(0.046)$ & 0.247 & $-0.034(0.038)$ & 0.370 \\
\hline Female sex & $-0.001(0.001)$ & 0.202 & $0.006(0.004)$ & 0.207 & $0.001(0.001)$ & 0.502 & $0.000(0.001)$ & 0.907 \\
\hline
\end{tabular}

\section{Relationship between cigarette smoking and disease onset of POAG}

As shown in Table 2, in the current study no association of cigarette smoking was found with disease onset of JOAG after adjusted for age and sex (adjusted $P=0.692$ ). Similarly, no association of cigarette smoking was found in disease onset of AOAG (adjusted $P=0.925$ ). No interaction between smoking and age/sex was detected in association with the disease onset (data not shown).

\section{Correlation between cigarette smoking and glaucoma- related biometric parameters}

We further examined the effects of cigarette smoking on glaucoma-related risk factors. Multiple linear regression analysis of VCDR, CCT and IOP were shown in Tables 3, 4, and 5. In controls, no significant effects of smoking were found on VCDR, IOP or CCT (all $P>0.05$ ). In JOAG, none of smoking, age and sex showed significant association with VCDR, IOP or CCT (all $P>0.05$ ). In AOAG, smoking was found to be significantly correlated with $\operatorname{CCT}(\beta \pm$ s.e. $=-32.7 \pm 11.9, P=0.009)$, but not with VCDR or IOP $(P=0.418$ and 0.111 respectively). Neither age nor sex was correlated with VCDR, IOP or CCT in AOAG (all $P>0.05$ ). A significant correlation between smoking and CCT was observed in combined POAG $(\mathrm{JOAG}+\mathrm{POAG})(\beta \pm$ s.e. $=-26.1 \pm 8.5 \mu \mathrm{m}, P=0.003)$. No interaction between smoking and age/sex was detected in association with the glaucoma-related biometric parameters (data not shown).

\section{Discussion}

According to World Health Organization data, smoking has become a serious global public health problem. Among the approximately 1.3 billion smokers in the world, over 6 million die annually due to tobacco exposure, especially in [10]. Cigarette smoking is related to many eye diseases such as cataract, age-related macular degeneration [11-13]. Existing studies on the relationship between cigarette smoking and POAG remain controversial. Findings vary among ethnic groups and study design. And most of these studies focused on AOAG. There are limited data of these studies in the Chinese population. Recently in a cohort of African-American women, Wise L. A. et al. reported that smoking might be associated with increased risk of early-onset POAG [14]. Kang, J. H. et al. also reported cigarette smoking conferring risk to POAG [15]. Similar findings were also reported in other independent studies [16-18]. But some other studies reported no association between smoking and POAG. In a prospective follow-up study from 1980 and 1986, respectively, to 1996, the results showed neither current smokers nor ex-smokers were at greater risk for POAG than those who had never smoked, and heavier smoking did not increase the risk of POAG [8]. And in a systematic review, Richard et al. also reported that there was little evidence for the association between smoking and POAG [19]. Other independent studies also reported lack of such association $[9,20]$. In our Chinese cohort, smoking was not found to confer risk to disease onset in either JOAG or AOAG. Our study thus did not support cigarette smoking as a risk factor of POAG onset.

Apart from disease onset, it remains to be elucidated whether cigarette smoking is related to IOP, CCT and VCDR, which are glaucoma risk factors. In 2003, Yoshida $\mathrm{M}$. et al. reported that cigarette smoking had a significantly positive association with the IOP in Japanese male individuals [21]. Lee A. J. et al. also reported similar association [22]. In the current study, although no significant association with IOP was observed, we found evidence that smoking could be correlated with decreased CCT in AOAG. As reported by previous studies, in individuals with thinner cornea, their IOP tends to be lower estimated [23-25]. In AOAG smokers, their IOP could possibly be lower estimated

Table 4 Multiple linear regression analysis of effects of smoking, age and female sex on intraocular pressure

\begin{tabular}{|c|c|c|c|c|c|c|c|c|}
\hline & \multicolumn{2}{|c|}{ Controls } & \multicolumn{2}{|c|}{ JOAG } & \multicolumn{2}{|c|}{ AOAG } & \multicolumn{2}{|c|}{ JOAG + AOAG } \\
\hline & $\beta$ (SE) & $P$ & $\beta$ (SE) & $P$ & $\beta$ (SE) & $P$ & $\beta$ (SE) & $P$ \\
\hline Smoking (Yes) & $-0.632(0.555)$ & 0.257 & $2.430(4.679)$ & 0.608 & $-3.885(2.764)$ & 0.163 & $-1.061(2.197)$ & 0.630 \\
\hline Age (Year) & $-0.583(0.658)$ & 0.377 & $3.741(5.520)$ & 0.504 & $-4.100(3.594)$ & 0.257 & $-0.471(2.859)$ & 0.869 \\
\hline Female sex & $-0.015(0.027)$ & 0.580 & $-0.055(0.289)$ & 0.851 & $-0.090(0.098)$ & 0.365 & $-0.071(0.056)$ & 0.206 \\
\hline
\end{tabular}


Table 5 Multiple linear regression analysis of effects of smoking, age and female sex on central corneal thickness

\begin{tabular}{|c|c|c|c|c|c|c|c|c|}
\hline & \multicolumn{2}{|c|}{ Controls } & \multicolumn{2}{|c|}{ JOAG } & \multicolumn{2}{|c|}{ AOAG } & \multicolumn{2}{|c|}{ JOAG + AOAG } \\
\hline & $\beta(\mathrm{SE})$ & $P$ & $\beta(\mathrm{SE})$ & $P$ & $\beta(\mathrm{SE})$ & $P$ & $\beta$ (SE) & $P$ \\
\hline Smoking (Yes) & $-1.3(7.8)$ & 0.865 & $-13.6(11.8)$ & 0.271 & $-32.7(11.9)$ & 0.009 & $-26.1(8.5)$ & 0.003 \\
\hline Age (Year) & $-16.3(9.2)$ & 0.080 & $-4.7(12.3)$ & 0.709 & $-23.2(14.9)$ & 0.128 & $-11.3(10.2)$ & 0.272 \\
\hline Female sex & $0.6(0.4)$ & 0.103 & $0.1(0.8)$ & 0.926 & $0.6(0.5)$ & 0.188 & $0.1(0.2)$ & 0.657 \\
\hline
\end{tabular}

due to thinner CCT. In addition, the change of CCT in POAG may affect the disease course. A previous study on corneal thickness and functional damage in patients with ocular hypertension showed that patients with ocular hypertension plus thinner cornea had a greater risk of developing functional damage over time [26].

The exact reason for decreased corneal thickness in POAG smokers remains unclear. However, cigarette smoking may exert this effect through hypoxia and collagen in the cornea. Smoking has been reported to decrease oxygen and collagen production in tissues during wound healing $[27,28]$. Ocular hypertension causes damage to the cornea [29]. Smoking probably deteriorates ocular hypoxia caused by ocular hypertension [27], and consequently affects the biosynthesis of collagen and extracellular matrix turnover [30], which could be an explanation to the decreased corneal thickness.

In the current study, cigarette smoking was not found to be associated with disease onset of POAG. However, the association of smoking with decreased CCT in POAG suggested that more attention should be paid on CCT in the early stage of POAG in smokers to estimate more correct target IOP in order to better reduce the early lesion of optic nerve. Current findings thus warranted further study.

\section{Conclusions}

In this study, although cigarette smoking was not found to be a risk factor for onset of POAG, it was correlated with CCT in AOAG, and thus might still play a role in the disease course, especially for AOAG.

\section{Additional file}

Additional file 1: Smoking Status Questionnaire.

\section{Competing interests}

The authors declare that they have no competing interests.

\section{Authors' contributions}

DW carried out the questionnaire, participated in statistical analysis and drafted the manuscript. $\mathrm{YH}$ and $\mathrm{CH}$ carried out the clinical examination in patients and controls. YZ participated in study coordination. PW and $J$ provided support of database software. YP and YL assisted in the statistical analysis and discussion. J-HC participated in the study design and statistical analysis. MZ conceived the study, participated in the study design and clinical examination, and wrote the manuscript. All authors read and approved the final manuscript.

\section{Acknowledgments}

This study was supported in part by Research Grants 81000397 from the National Natural Science Foundation of China; 8151503102000019 from the Natural Science Foundation of Guangdong Province, China; 2010 B031600130 from the Science and Technology Planning Project of Guangdong Province, China; and 10-020, 10-021, and 10-022 from the Joint Shantou International Eye Center, Shantou University/The Chinese University of Hong Kong.

Received: 26 November 2011 Accepted: 14 November 2012

Published: 27 November 2012

\section{References}

1. Quigley HA, Broman AT: The number of people with glaucoma worldwide in 2010 and 2020. Br J Ophthalmol 2006, 90(3):262-267.

2. Rao KN, Nagireddy S, Chakrabarti S: Complex genetic mechanisms in glaucoma: an overview. Indian J Ophthalmol 2011, 59(Suppl):S31-S42.

3. Fan BJ, Leung YF, Wang N, Lam SC, Liu Y, Tam OS, Pang CP: Genetic and environmental risk factors for primary open-angle glaucoma. Chin Med J (Engl) 2004, 117(5):706-710.

4. Raymond $\mathrm{V}$ : Molecular genetics of the glaucomas: mapping of the first five "GLC" loci. Am J Hum Genet 1997, 60(2):272-277.

5. Leske MC: The epidemiology of open-angle glaucoma: a review. Am J Epidemiol 1983, 118(2):166-191.

6. Cheng AC, Pang CP, Leung AT, Chua JK, Fan DS, Lam DS: The association between cigarette smoking and ocular diseases. Hong Kong Med J 2000, 6(2):195-202.

7. Solberg $Y$, Rosner $M$, Belkin M: The association between cigarette smoking and ocular diseases. Surv Ophthalmol 1998, 42(6):535-547.

8. Kang JH, Pasquale LR, Rosner BA, Willett WC, Egan KM, Faberowski N, Hankinson SE: Prospective study of cigarette smoking and the risk of primary open-angle glaucoma. Arch Ophthalmol 2003, 121(12):1762-1768.

9. Klein BE, Klein R, Ritter LL: Relationship of drinking alcohol and smoking to prevalence of open-angle glaucoma. The Beaver Dam Eye Study. Ophthalmology 1993, 100(11):1609-1613.

10. Wipfli H, Samet JM: Global economic and health benefits of tobacco control: part 1. Clin Pharmacol Ther 2009, 86(3):263-271.

11. Thornton J, Edwards R, Mitchell P, Harrison RA, Buchan I, Kelly SP: Smoking and age-related macular degeneration: a review of association. Eye (Lond) 2005, 19(9):935-944.

12. Lois N, Abdelkader E, Reglitz K, Garden C, Ayres JG: Environmental tobacco smoke exposure and eye disease. Br J Ophthalmol 2008, 92(10):1304-1310.

13. Cong R, Zhou B, Sun Q, Gu H, Tang N, Wang B: Smoking and the risk of age-related macular degeneration: a meta-analysis. Ann Epidemiol 2008, 18(8):647-656.

14. Wise LA, Rosenberg L, Radin RG, Mattox C, Yang EB, Palmer JR, Seddon JM: A prospective study of diabetes, lifestyle factors, and glaucoma among African-American women. Ann Epidemiol 2011, 21(6):430-439.

15. Kang JH, Wiggs $J \mathrm{~L}$, Rosner BA, Haines J, Abdrabou W, Pasquale LR: Endothelial nitric oxide synthase gene variants and primary open-angle glaucoma: interactions with hypertension, alcohol intake, and cigarette smoking. Arch Ophthalmol 2011, 129(6):773-780.

16. Mehra KS, Roy PN, Khare BB: Tobacco smoking and glaucoma. Ann Ophthalmol 1976, 8(4):462-464.

17. Wilson MR, Hertzmark E, Walker AM, Childs-Shaw K, Epstein DL: A casecontrol study of risk factors in open angle glaucoma. Arch Ophthalmol 1987, 105(8):1066-1071.

18. Bonovas S, Filioussi K, Tsantes A, Peponis V: Epidemiological association between cigarette smoking and primary open-angle glaucoma: a metaanalysis. Public Health 2004, 118(4):256-261. 
19. Edwards R, Thornton J, Ajit R, Harrison RA, Kelly SP: Cigarette smoking and primary open angle glaucoma: a systematic review. J Glaucoma 2008, 17(7):558-566.

20. Ponte F, Giuffre G, Giammanco R, Dardanoni G: Risk factors of ocular hypertension and glaucoma. The casteldaccia Eye study. Doc Ophthalmol 1994, 85(3):203-210.

21. Yoshida M, Ishikawa M, Kokaze A, Sekine Y, Matsunaga N, Uchida Y, Takashima Y: Association of life-style with intraocular pressure in middleaged and older Japanese residents. Jpn J Ophthalmol 2003, 47(2):191-198.

22. Lee AJ, Rochtchina E, Wang JJ, Healey PR, Mitchell P: Does smoking affect intraocular pressure? findings from the blue mountains Eye study. J Glaucoma 2003, 12(3):209-212.

23. Avitabile T, Longo A, Rocca D, Amato R, Gagliano C, Castaing M: The influence of refractive errors on IOP measurement by rebound tonometry (ICare) and Goldmann applanation tonometry. Graefes Arch Clin Exp Ophthalmol 2010, 248(4):585-591.

24. Ehlers $\mathrm{N}$ : On corneal thickness and intraocular pressure. II. A clinical study on the thickness of the corneal stroma in glaucomatous eyes. Acta Ophthalmol (Copenh) 1970, 48(6):1107-1112.

25. Kohlhaas M, Boehm AG, Spoerl E, Pursten A, Grein HJ, Pillunat LE: Effect of central corneal thickness, corneal curvature, and axial length on applanation tonometry. Arch Ophthalmol 2006, 124(4):471-476.

26. Zeppieri $M$, Brusini $P$, Miglior S: Corneal thickness and functional damage in patients with ocular hypertension. Eur J Ophthalmol 2005, 15(2):196-201.

27. Jensen JA, Goodson WH, Hopf HW, Hunt TK: Cigarette smoking decreases tissue oxygen. Arch Surg 1991, 126(9):1131-1134.

28. Jorgensen LN, Kallehave F, Christensen E, Siana JE, Gottrup F: Less collagen production in smokers. Surgery 1998, 123(4):450-455.

29. Melamed S, Ben-Sira I, Ben-Shaul Y: Corneal endothelial changes under induced intraocular pressure elevation: a scanning and transmission electron microscopic study in rabbits. Br J Ophthalmol 1980, 64(3):164-169.

30. Knuutinen A, Kokkonen N, Risteli J, Vahakangas K, Kallioinen M, Salo T, Sorsa T, Oikarinen A: Smoking affects collagen synthesis and extracellular matrix turnover in human skin. Br J Dermatol 2002, 146(4):588-594.

doi:10.1186/1471-2415-12-59

Cite this article as: Wang et al: Association analysis of cigarette smoking with onset of primary open-angle glaucoma and glaucomarelated biometric parameters. BMC Ophthalmology 2012 12:59.

\section{Submit your next manuscript to BioMed Central and take full advantage of:}

- Convenient online submission

- Thorough peer review

- No space constraints or color figure charges

- Immediate publication on acceptance

- Inclusion in PubMed, CAS, Scopus and Google Scholar

- Research which is freely available for redistribution 